\title{
한국의 중동지역 개발협력 현황과 추진 전략
}

강 황 욱 KOICA 중동·아프간팀 과장

\section{I. 서 언}

중동 및 북아프리카 등 아랍 국가들은 이슬람혁명 이후 가장 큰 변혁의 시기를 맞이하고 있다. 튀 니지의 대졸 노점상 모하메드 부아지지의 분신 이후 시작된 민주화 시위는 이집트로 번져 37년간 집 권하던 무바라크를 퇴진시켰고, 리비아에서는 42 년 독재 권력 카다피와 이에 대항하는 반군과의 내 전 사태로 확대되었다. 최근 리비아의 독재권력 카다피가 축출되어 과도정부가 구성된 후 국제사회 의 지원이 논의되고 있다. 이 외에도 시리아에도 대정부 시위가 벌어지고 있으며, 예멘, 바레인 등의 왕정도 위협을 받고 있다. 이처럼 철옹성처럼 군림하던 아랍의 독재자들이 하나 둘 권좌에서 내려오 며 세계사의 한 획을 긋고 있다.

중동 민주화는 독재권력의 오랜 권위주의와 부정부패에 대한 반발로 일어났으며, 경제적으로도 높 은 실업률과 인플레이션 그리고 사회 양극화에 대한 불만이 크게 고조되어 발생하였다. 1990년대 들 어서 아랍국가들도 IMF의 권고에 따라 경제자유화를 추진하였으며 2000년대 들어서는 표면적으로 높은 경제성장률을 구가하기 시작했다. 그러나 그 이면에는 높은 청년실업과 물가 급등으로 사회 양 극화가 심각해졌고 이는 민주화 시위의 한 원인이 되었다.

중동(中東, The Middle East)이라는 용어는 본래 19세기 영국에서 극동(極東; Far East)과 근동 (近東; Near East)의 중간 지역을 지칭하기 위해서 생겨난 지역적 개념으로 제 2 차 세계대전 중에 영 국이 이집트에 중동 사령부(Middle East Command)를 설치함에 따라 오늘날 널리 사용되고 있다. 


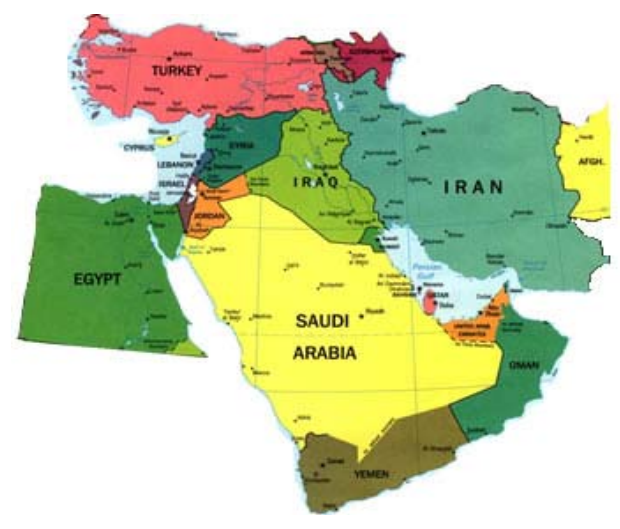

이와 같이 '중동'은 상대적인 개념으로 그 범위가 명 확하지 않으나, 이집트, 튀니지, 리비아 등은 지리적 으로 '중동'이 아니라 '북아프리카'로 봐야 하며 역사, 언어, 문화적으로 같은 '아랍' 국가로 봐야 할 것이다.

중동 국가는 역사, 언어, 문화, 종교 및 인종적인 공 통점을 배경으로 통상 지리적으로는 동지중해로부터 페르시아만까지 이르는 지역에 포함된 국가들을 말하 며 3 개국(이스라엘, 터키, 이란)을 제외한 나머지는 아 랍 국가이고, 이스라엘을 제외한 대부분의 국가는 이

슬람 국가이다.

〈표 1〉 중동지역 국가의 주요 지표

\begin{tabular}{|c|c|c|c|c|c|}
\hline 구분 & 이라크 & 예멘 & 요르단 & 이란 & 팔레스타인 \\
\hline 종족(\%) & $\begin{array}{l}\text { 아랍인(73.5), } \\
\text { 쿠르드인(21) }\end{array}$ & 아랍인 & 아랍인 & $\begin{array}{c}\text { 페르시아인(51), } \\
\text { 아제르바이잔인(24) }\end{array}$ & 팔레스타인인 \\
\hline 언어 & $\begin{array}{l}\text { 아랍어 } \\
\text { /쿠르드어 }\end{array}$ & 아랍어 & 아랍어 & 페르시아어 & 아랍어 \\
\hline 1인당 GN(\$)* & 3,340 & 2,340 & 5,840 & 11,490 & $1,230^{* * * *}$ \\
\hline 인간개발지수** & na & 0.575/140위 & 0.770/96위 & 0.782/88위 & 0.737/110위 \\
\hline 기대수명(세)** & 67.8/ na & 62.5/129위 & 72.4/77위 & 71.2/95위 & 73.3/66위 \\
\hline 문자해독율 $(\%)^{* *}$ & 74.1/ na & 58.9/128위 & 91.1/64위 & 81.3/94위 & 93.8/53위 \\
\hline $\begin{array}{l}\text { 부패인식지수 } \\
\text { (2009년)*** }^{* * *}\end{array}$ & 1.5/176위 & 5.0/49위 & 2.1/154위 & 1.8/168위 & na \\
\hline 경제 성장률***** & $9.8 \%$ & $4.7 \%$ & $5.5 \%$ & $4.3 \%$ & \\
\hline
\end{tabular}

자료 : * World Bank(2009). World Development Indicators data base, http://data.worldbank.org/indicator

** UNDP(2009), Human Development Index

*** 국제투명성기구(2009). 부패인식지수(The Corruption Perceptions Index)

$\star * * *$ UNHCR(2008), http://www.unicef.org/infobycountry/oPt_statistics.html

$\star * \star * *$ IMF world economy outlook 2011 


\section{II. 한국의 중동지역 지원 현황}

\section{1. 중동 지역 지원 현황}

중동지역 대부분의 국가가 이슬람교를 신봉하고 아랍어를 사용하여 사회, 문화적 배경은 유사하나 국가별 경제사회개발 여건은 각기 다르다. 석유 등 천연자원이 풍부한 산유국들은 석유 수출로 경제, 사회발전을 이루고 고도의 기반산업을 갖춘 반면 예멘과 같은 최빈국도 있다. ${ }^{1)}$

또한, 중동지역은 2 차 대전후 아랍-이스라엘 분쟁, 이란·이라크 전쟁, 걸프전 등 무력전쟁과 이 슬람 과격주의자의 테러 위협 때문에 대표적인 국제적 분쟁지역으로 꼽히며, 경제적으로는 세계경제 에서 차지하는 비중이 $4 \%$ 정도에 불과하지만 석유자원의 중요성 때문에 항상 주목의 대상이 되어 왔다. ${ }^{2)}$

\section{〈그림 1〉 중동지역 지원실적}

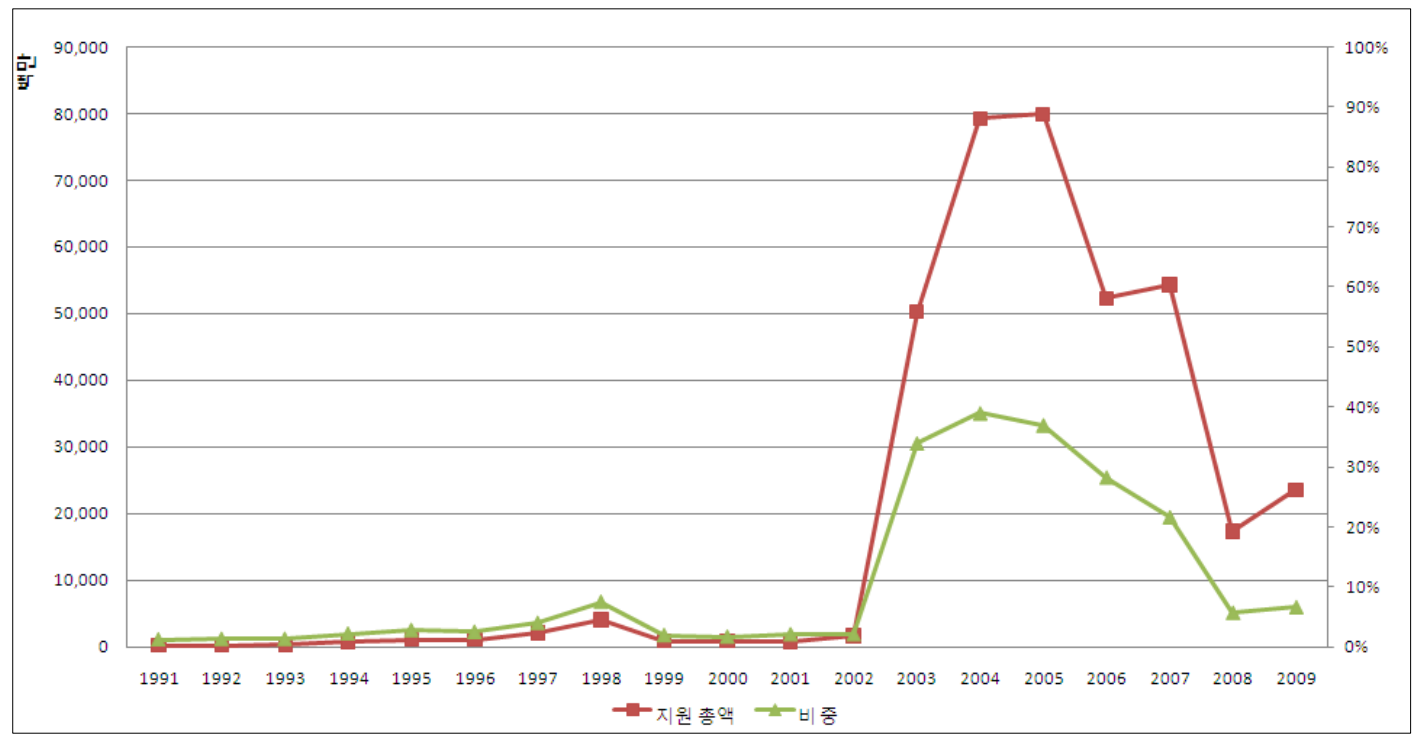

한국은 중동지역에 대한 무상원조를 1991 2009년간 총 3억5천만불을 지원하였으며, 이는 전체 사업비의 $17 \%$ 에 해당한다. 1990 년대 한 자릿수에 불과하던 중동지역 지원 비중이 2003년에는 이라 크 전후 복구 지원을 계기로 $34 \%$ 까지 증가하였으며, 2005 09년간 중동지역의 지원규모는 전체 지 원액의 $22 \%$ 를 차지하였다. 특히, 중동지역의 평화 정착을 위한 이라크 전후복구지원과 팔레스타인

1) 2011년 중동 지역은 4.2\%의 완만한 경제 성장을 달성할 것으로 IMF는 예상하고 있다.

2) 중동은 전세계 원유 매장량의 약 $65 \%$, 생산량의 약 $36 \%$ 를 차지하고 있다. 
문제해결을 통한 중동평화 정착을 지원하고 있다.

〈그림 2〉 중동지역 분야별 지원 비율

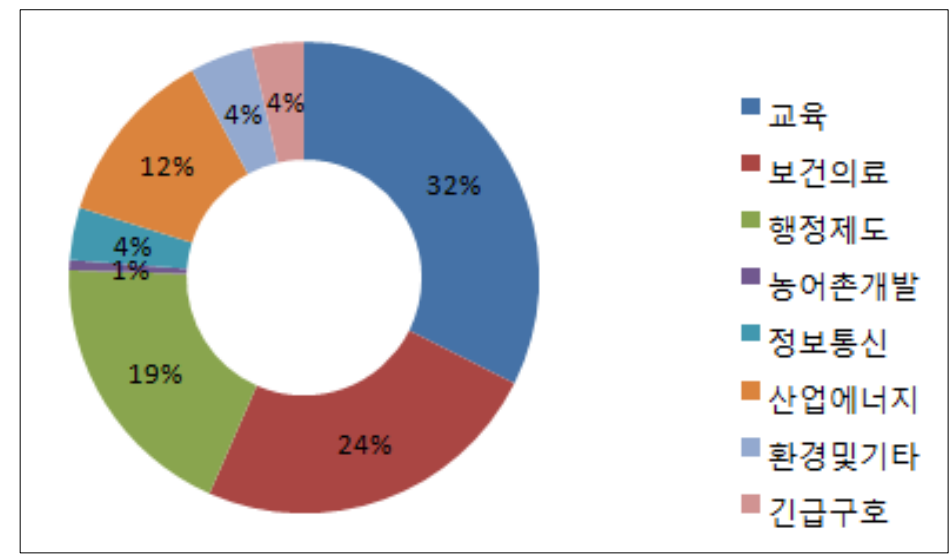

출처 : KOICA 통계 자료

특히, 〈그림 2 〉와 같이 전쟁 등으로 병원, 학교 등 기본적인 인프라 시설이 부족한 중동 지역 전후 복구를 위해 교육, 보건의료 등 기본 사회 인프라 지원에 중점적으로 지원하고 있다.

\section{2. 국가별 지원 현황}

중동지역은 국가별로 경제 - 사회의 발전정도가 매우 다양하여 국별 지원내용이 상이하나 대체로 경제 개발정책 등 정부역량 강화를 위한 행정제도 분야, 기초보건 의료서비스의 역량과 접근성 강화 를 위한 보건의료 분야, 빈곤층의 소득 향상을 위한 직업훈련 및 $\mathrm{MDG}$ 달성을 위한 초등교육, 향후 경제협력을 고려한 산업에너지 분야 지원를 중점적으로 지원하고 있다.

한국의 중동지역 지원 국가는 이라크와 팔레스타인에 대한 재건복구 지원국과 요르단, 예멘 등의 일반협력국으로 구분된다.

한국은 2010년 국제개발협력위원회에서 유· 무상 통합 협력대상국을 26 개로 조정하면서 중동 지 역 국가중 이라크를 아프가니스탄과 함께 특별협력국으로, 팔레스타인, 요르단, 이란, 예멘을 일반협 력국으로 지정하였다.

재건복구 지원은 주로 교육과 보건의료 분야 중심의 사회 인프라 시설 지원과 연수생 초청을 통한 인적 자원 개발을 중점 지원하고 있으며 일반협력국은 대상 국가의 경제사회 발전을 감안하여 인프 라 시설 지원 및 기술협력 지원을 실시하고 있다. 


\section{〈그림 3〉 중동지역 국가별 지원 비율}

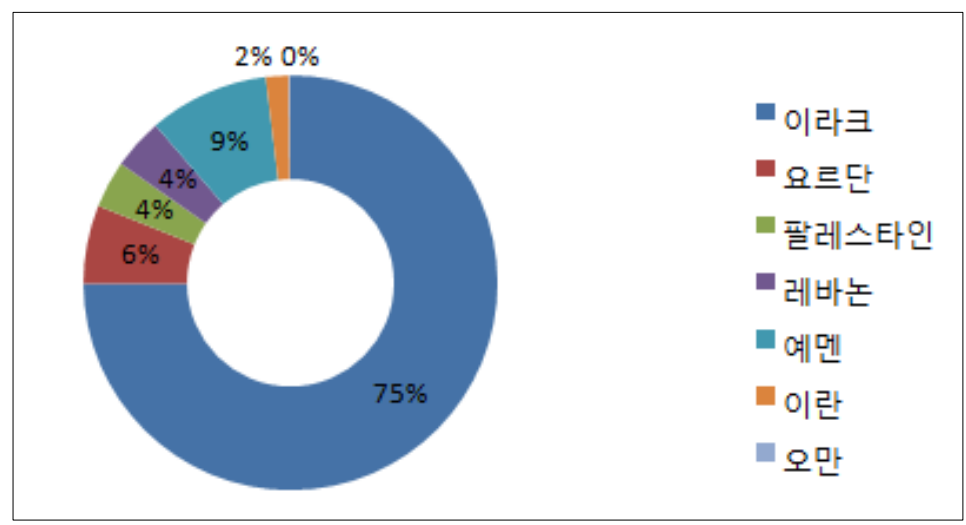

출처 : $\mathrm{KOICA}$ 통계 자료

한국은 위〈그림 3〉에서 보듯이 한국은 중동지역에서 이라크, 팔레스타인 등 전후 복구를 위한 평 화구축 대상 국가에 중점적으로 지원하고 있다. 이처럼 현재까지 한국의 중동지역 지원은 이라크, 팔 레스타인에 대한 평화 구축 지원 등 전후 재건복구 성격이 두드러진다.

\section{$\square$ 이라크}

우리 정부는 '03.10월 마드리드 원조공여국회의 시 '03-'07년간 이라크 재건사업에 총 2.6억불 지 원키로 서약하였으며, '07.5월 이집트에서 개최된 ICI(International Compact for Iraq)회의 시 '08 '11년간 총 2억불(무상 1 억불 및 유상 1억불) 추가지원 서약하였다. 그러나 이라크의 치안사정 악화로 사업추진이 지연되어 2011년 현재 서약한 1 억불 중 약 4,500만불을 집행하고, 2013년까지 잔 여 서약 사항을 이행키로 했다.

지금까지 이라크 국가개발전략(NDS)과 UN 및 세계은행의 재건우선순위, 우리의 이라크 재건지원 사업 경험 및 향후 지원방향 등을 고려하여 대 이라크 지원전략의 핵심 분야로 우리의 비교우위 분야 인 교육, 보건, 도시 공공서비스 개선 등에 집중지원하고 있다.

〈표 2〉KOICA 이라크 지원 실적

(단위 :만불)

\begin{tabular}{c|c|c|c|c|c|c|c|c|c|c|c|c}
\hline 연도 & $91-00$ & 01 & 02 & 03 & 04 & 05 & 06 & 07 & 08 & 09 & 10 & 계 \\
\hline 지원액 & 59 & 3 & 1 & 4,057 & 6,008 & 7,383 & 4,820 & 4,664 & 644 & 650 & 1,183 & 29,472 \\
\hline
\end{tabular}

종전 직후 본격화한 국제사회의 이라크 재건지원으로 이라크는 민주주의와 시장경제체제로 신속 하게 전환하며 국가 재건에 힘쓰고 있으나, 다양한 종파. 정파간의 이해관계 및 외부 저항세력의 계 속된 방해로 인해 개발환경이 매우 불안정하다. 특히, 최근 중동지역의 민주주의 및 실업해소를 위한 
대규모 시위가 경제발전 및 재건 사업의 속도가 더딘 이라크에도 영향을 미쳐 전국적으로 대규모 시 위가 발생하였고, 2011년 상반기에만 20여회의 테러가 발생하였다.

말리키 총리는 2014년 임기 만료 후 3선 도전을 포기하며, 26만불에 달하는 자신의 연봉을 $50 \%$ 삭감하고 국고로 환수 하겠다고 밝혔다. 아울러, 사회복지 및 국가재건을 위해 치안 관련예산을 식량 수급 및 국가재건에 활용할 계획을 발표하기에 이르렀다.

이러한 치안상황의 지속적인 악화에도 불구, 우리 정부의 재건사업은 타 공여국 및 원조기관과 비 교해 현장중심의 가시적인 사업으로서 그간 이라크 경제사회개발에 기여한 것으로 평가되고 있고, 특히 이라크 정부와의 원조조정 및 협의체계를 유지하면서 이라크의 국가개발전략(NDS)에 기초한 사업을 실시하고 있다.

\section{팔레스타인}

최근 팔레스타인 자치정부는 2011년 9월 UN총회에서 독립국가 승인을 추진키로 발표하였다. 그러 나, 미국과 독일이 이에 반대하고 있어 통과 여부는 불투명하다. 이와 같은 이스라엘-팔레스타인간 평화협상과 팔레스타인 독립 여부에 대한 국제사회의 관심이 높아지고 있으며 국제사회의 대 팔레스 타인 원조규모는 지속적으로 확대되고 있다.

\section{〈표 3〉 국제사회 팔레스타인 원조 규모}

(단위 : 백만불)

\begin{tabular}{c|c|c|c|c}
\hline 연도 & 2006 & 2007 & 2008 & 2009 \\
\hline 금액 & 1,016 & 1,373 & 2,060 & 2,282 \\
\hline
\end{tabular}

출처 : $\mathrm{OECD}$ 통계

한국은 '07.12월 파리에서 열린 팔레스타인 공여국회의시 3년간('08-'10년) 2천만불 지원을 약속 하였고, 2010년 2월 이명박 대통령은 압바스 자치정부수반 방한시에 향후 5년간(2011 2015) 총 2천 만불 지원을 약속하였다. 팔레스타인 정부는 국가개발전략의 주요 4대 목표로 (1) 보건, 교육, 주택건 설 등 삶의 질 향상, (2) 굿거버넌스 (3) 안전 및 치안 (4) 경제 활성화 등을 중점으로 두고 있으며 한국 의 지원 프로그램은 팔레스타인 개발전략에 중점분야를 맞춰 기초교육 및 기술교육시스템 강화, 기 초보건의료 서비스 역량강화, 행정역량강화로 설정하고 있다.

〈표 4〉 KOICA 팔레스타인 지원 실적

(단위 : 만불)

\begin{tabular}{c|c|c|c|c|c|c|c|c|c|c|c|c}
\hline 연도 & $91-00$ & 01 & 02 & 03 & 04 & 05 & 06 & 07 & 08 & 09 & 10 & 계 \\
\hline 지원액 & 543 & 2 & 45 & 64 & 367 & 165 & 118 & 34 & 245 & 744 & 710 & 3,037 \\
\hline
\end{tabular}

출처 : $\mathrm{KOICA}$ 통계 


\section{요르단}

한국은 요르단 국가개발계획에 맞춰 직업훈련원 건립 및 기능인력 양성을 통한 인적자원 개발, 경 제개발 전략 수립, 수자원 개발분야에 중점 지원하고 있으며, 요르단은 대중동 정치적, 경제적 관문 으로 분쟁국가에 대한 원격 관할지 역할 등 역내 거점 협력국 역할을 하고 있다.

〈표 5〉 KOICA 요르단 지원 실적

(단위 :만불)

\begin{tabular}{c|c|c|c|c|c|c|c|c|c|c|c|c}
\hline 연도 & $91-00$ & 01 & 02 & 03 & 04 & 05 & 06 & 07 & 08 & 09 & 10 & 계 \\
\hline 지원액 & 172 & 12 & 6 & 6 & 124 & 160 & 319 & 244 & 384 & 400 & 451 & 2,278 \\
\hline
\end{tabular}

\section{III. 한국의 중동지역 지원 전략}

\section{$\square$ 중동 평화정착을 위한 중장기적 전략 수립}

$\mathrm{OECD}$ 는 정치적으로 정권의 권위와 정당성이 부족하며, 국가 행정적으로 기본적인 공공서비스를 제공할 능력과 의지가 미흡하고 내부적인 폭력과 외부적인 위기상황에 의해 안전이 보장되지 않은 국가를 취약국가로 정의하고 있다. 이러한 기준으로 볼 때 최근 중동 지역 국가들의 지배세력에 대한 불만 표출로 인해 야기된 민주화 시위중동 대부분의 국가가 취약국가 또는 취약국가에 근접해 있다 고 볼 수 있다.

〈그림 3〉에서 보듯이 현재까지 한국의 중동지역 지원은 이라크, 팔레스타인 등 중동 지역내 분쟁 및 취약국가를 대상으로 한 전후 재건복구 성격이 뚜렷하다.

그러나, 분쟁 및 취약국에 대한 정책적 전략에 따른 것이 아니라 전후복구에 대한 국제사회의 요 구 및 한국의 외교정책에 따른 단기간의 집중적 지원이 이루어져 중동에 대한 지원 금액도 점진적 증 감이 있는 것이 아니라 연도별로 편차가 심한 편이다. 앞으로도 중동지역에 대한 지원은 국가 정책차 원에서 결정될 가능성이 높다. 이러한 외부 환경에 대해 KOICA 등 국제개발협력 관련 기관에서는 중 동 지역 국가에 대한 장기적 관점에서 한국의 비교우위를 바탕으로 한 지원 전략을 수립하여 외교안 보적 결정 사항에 대처할 필요가 있다. 중동 지역은 역내 국가들의 대내외적 정치 경제적 환경 변화 가능성이 높고, 이로 인한 한국의 지원 규모 등 외교 정책이 변화가 클 수 있으나, 지원 목적 및 지원 방향에 대한 중장기적 계획을 통해 일관성 있게 추진할 수 있을 것이다.

우리나라의 지원 금액이 타 공여국에 비해 상대적으로 소규모이며 정치적, 군사적으로도 대상 국 가에 대한 영향력은 클 수 없으나, 우리나라 전후 경제개발 성공 경험 등 고유한 경험을 바탕으로 이 를 중동 지역 국가들에게 전수할 수 있는 모범 사례가 될 수 있다. 


\section{한국 경제발전 경험공유 집중지원}

중동지역은 국가별 개발여건의 차별성에 따른 국별 특성화전략을 통해 우리나라가 가지고 있는 성 공적인 전후 경제개발 경험을 적극 공유함으로써 정부 및 사회 전반에 재건을 위한 동기를 부여할 수 있는 곳이다.

우리나라의 성공적인 전후 복구 및 산업인력 양성 등을 통한 경제 발전 경험은 중동 국가 발전의 모범 사례가 되고 있으며, 앞으로는 민주주의 제도 도입과 정착을 위해 우리나라 민주화 경험이 중동 지역 민주화 정착에 훌륭한 사례로 적용될 수 있을 것이다.

중동 국가중 기본적인 사회 인프라가 부족한 분쟁 및 취약국가를 대상으로는 교육, 보건의료 등 기본적인 사회 인프라 구축에 초점을 맞추되, 경제 개발 등 정부의 능력과 의지를 향상시킬 수 있는 행정역량 강화에도 주안점을 두어야 한다. 우리나라의 대표적인 비교우위 분야이자 경제발전의 동력 이 되는 직업훈련 지원을 통해 우수한 산업인력을 양성하고 이를 통한 소득 증대도 꾀할 수 있고, 병 원 건립 등 기본적 의료서비스 제공을 통한 삶의 질 향상을 도모할 필요가 있다.

또한, 석유 등 자원에 대한 의존도가 높은 중동 국가에는 높은 자원 의존도가 장기적으로 오히려 경제발전을 제약하는 요인이 될 수 있는 만큼 석유 의존도를 낮추고 비석유 부문 경제 강화를 위한 대체 에너지 개발 등 산업의 다양화를 위한 정책 제언이 필요할 것이다.

한국의 신도시 건설 추진의 경험을 전수하는 신도시 개발 마스터 플랜이나 산업 다각화 정책을 위 해서는 한국의 중화학공업 육성 정책 등을 전수할 수 있다.

한국 고유의 발전 경험을 바탕으로 한 지원 전략 수립에 노르웨이의 경험 공유 프로그램인 "Oil for Development"를 주목할 필요가 있다. 노르웨이는 효과적인 정부 정책을 통해 석유와 가스에서 얻어지는 자원을 지속 가능한 개발이 되도록 관리하고 있는데 이러한 고유의 경험을 산유국들과 공 유하고 있다. 노르웨이는 이 프로그램을 통해 석유에 대한 정부 정책, 관련 부처 및 민간 기관간의 협력 체계 등을 전수하고 있다.

또한, 오스트리아는 대분의 공여국들이 비교우위로 내세우는 농업 분야에 대해 에티오피아에서 유 기농 농업이라는 틈새 분야를 설정하여 지원하는 전략을 갖고 있다.

한국은 중동과 지금까지 구축된 석유와 건설 분야 등 경제적 협력관계를 뛰어넘어 민주화 경험을 공유하는 더욱 발전된 협력 관계를 구축해 나갈 수 있을 것이다. 우리의 민주화 경험은 중동 국가들 에게 훌륭한 사례로 전수할 수 있을 것이며, 우리는 이러한 민주화 경험을 어떻게 전수해줄 수 있는 지 지원 전략을 수립해야 한다.

이집트, 튀니지 등 북아프리카· 중동국가들의 민주화에 대한 대내외적 관심이 높아지고 있으며 이 러한 민주주의 제도의 도입 및 정착을 위해 국제사회의 지원 또한 늘어나고 있다.

호주는 '이집트 민주화 프렌즈(Friends of Democratic Egypt)' 그룹 창설을 준비하며 우리나라의 참여를 원하고 있으며, 이집트 또한 우리나라 민주화 경험에 높은 관심을 표명하며 관련 노하우 전수 
를 요청하고 있다. 이러한 중동 지역에 대한 민주주의 정착을 위한 구체적인 방안으로는 해당 국가 선거관계자를 초청하여 ‘중동 민주화 특별연수’ 개설하여 선거관리 시스템을 전수하는 방안이 있을 수 있다. KOICA는 2011년도 민주화관련 연수초청사업으로 방글라데시 선거관리위원회 선거관리 역 량강화 초청연수를 계획한 바 있어 중동지역에 대해서도 선거관리 연수를 적기에 실시한다면 그 효 과가 클 것이다. 아울러, 중장기 자문단을 활용, 각 국의 민주화를 위한 우리나라의 민주화 경험 및 자문 지원도 병행할 수 있다.

\section{$\square$ 만성적인 식수 및 용수부족 국가에 대한 수자원 개발 지원 강화}

중동 지역 국가들의 발전에 가장 큰 관건은 수자원이다. 중동지역 물 수요가 급격히 증가하고 있 지만 중동지역에서 사용할 수 있는 물은 절대적으로 부족한 현실이다.

중동지역은 대표적인 물 부족지역으로, 중동지역 인구는 세계인구의 $5 \%$ 를 차지하지만 전세계 수 자원의 $1 \%$ 에 의지하고 있다.

석유 매장량이 전 세계의 3 분의 2 를 넘는 등 지하자원은 풍부하지만 수자원이 부족한 것이 발전의 큰 걸림돌이다. 중동지역의 주요한 수자원은 요르단강, 나일강, 티그리스-유프라테스강이지만 이 지 역이 모두 물 분쟁의 위험성을 안고 있다. 2001년 초 요르단강 상류 수자원을 레바논에서 끌어들여 이스라엘 갈릴리 호수로 들어오는 유량이 줄어들었다. 이에 이스라엘과 레바논간 분쟁의 전운이 감 돌았으며 이스라엘은 과거 시리아가 요르단강 상류의 물길을 바꾸려 하자 전투기로 건설장비를 파괴 했다. 또한, 티그리스 강과 유프라테스강의 수원이 있는 터키에서는 1970년대부터 GAP(동부아나톨 리아계발계획)을 수립하여 강 상류 지역에 22 개의 댐과 19 개의 발전소를 건설하고 있어 이 강들이 흐르는 시리아와 이라크에는 유량이 감소함에 따라 수자원 문제는 세 국가간 분쟁 요인이 되고 있다.

그러나 역내 국가들간 수자원 공동 개발에 대한 모범 사례도 있다.

나일강 인근 9개국에 의해 제창된 '나일강 유역 이니셔티브(Nile Basin Initiative)'가 그것이다. 이들 나일강 인근 국가들은 만성적인 물 부족, 가난, 치안 불안 등의 문제를 겪어 왔으며 최근 급속 한 인구증가로 물 수요 급증에 따른 수급 불안을 겪어 왔다. 이에 따라 역내 국가들의 협력 필요성이 증가하여 나일장 유역 공통 수자원의 공평한 사용과 그에 따른 혜택을 통해 지속 가능한 경제 사회적 발전을 이루는 것을 목표로 추진되고 있다.

이라크의 경우 상하수도 인프라는 2003년 종전 후 국가시설에 대한 적대새력의 테러 및 약탈로 주 요 장비가 파괴되거나 도난당하여 시급한 복구를 필요한 분야이다. 더욱이, 전력부족으로 인한 상수 도 시설의 펌프 및 정수가 어려워 물 공급이 매우 제한적이고 식수 오염이 심각하다. 2008년도 이라 크 기획부 조사에 따르면 이라크 전체의 $91 \%$ 가 깨끗한 식수접근에 어려움을 겪고 있으며 이 중 도훅 지방은 동 수치가 $98.2 \%$ 에 해당하는 등 심각한 식수문제에 시달리고 있다. 이로 인한 만성적인 식수 및 용수가 부족하여 식수원 개발 및 수자원 관리에 대한 지원이 절실히 필요한 실정이다. 
〈표 6〉 중동지역 수자원 관련 지원 내역

\begin{tabular}{|c|c|}
\hline 국 가 & 사업내용 (사업기간 / 지원규모) \\
\hline \multirow{5}{*}{ 이라크 } & 상하수도 현대화사업('05-'06, 600만불) \\
\hline & 아르빌 소수력발전소 건립사업('05-'07, 980만불) \\
\hline & 이라크 아르빌 상수도 침사지 설치사업('09-'11/350만불) \\
\hline & 이라크 도훅 식수공급개선사업('11-'13/300만불) \\
\hline & 아르빌 상하수도 현대화 시범사업('05-'07/600만불) \\
\hline \multirow{7}{*}{ 요르단 } & 요르단 폐수처리시설 확장 타당성조사'09/97만불) \\
\hline & 수질모니터링 시스템구축사업('08-'10/350만불) \\
\hline & 와디에시르 폐수처리사업(10백만불/EDCF) \\
\hline & 마다바 폐수처리시설 확충사업(9백만불/EDCF) \\
\hline & 암만 남부 폐수처리 1차사업(24백만불/EDCF) \\
\hline & 나우르 폐수처리사업(20백만불/EDCF) \\
\hline & 암만 남부 폐수처리 2차사업(74백만불/EDCF) \\
\hline
\end{tabular}

자료 : 한국국제협력단

\section{$\square$ 중동 지역의 특수성을 감안한 사업 추진}

중동지역 사업수행시 가장 큰 걸림돌은 치안 상황이다. 이라크에서는 2011년 상반기에만 20여회 의 테러가 발생하는 등 중동지역 국가들의 불안한 치안사정으로 요르단을 제외한 나머지 국가에는 $\mathrm{WFK}$ 봉사단원을 파견할 수 없는 실정이다. 또한, 이라크는 $\mathrm{KRG}$ (쿠르드 자치정부) 지역을 제외한 나머지 지역은 치안 사정으로 사업 추진 인력의 이동도 극히 제한되고 있다. 이로 인해 이라크 사업 추진시에는 제 3 국 원격회의 등을 통한 간접적인 방식으로 사업을 추진하고 있다. 이러한 치안 여건 으로 인해 물자지원 위주의 단순한 사업 추진에만 한정되는 경향이 있다. 그리고 2008년 이스라엘의 가자 침공과 같이 역내 국가간 첨예한 대립 환경은 돌발적인 상황을 일으킬 수 있으며 아직 꺼지지 않은 중동 민주화 시위가 언제 다시 일어나 정국을 혼란스럽게 할지도 알 수 없는 만큼 사업 추진시 에는 대내외적인 치안 상황을 면밀히 검토하고 상황 악화시 출구 전략도 수립할 필요가 있다. 


\section{IV. 결 언}

위에서 살펴 본 바와 같이, 중동지역 국가들은 아랍과 이슬람이라는 문화적, 역사적, 언어적, 종교 적 공통점을 갖고 있으나, 석유 등 천연 자원 보유 여부에 따라 국가마다 각기 다양한 경제적 발전 여건을 갖고 있다.

지금까지 한국은 이라크, 팔레스타인 등 중동지역에 대해 대체로 외교안보적 관점에서 지원 여부 가 결정되어 온 것이 사실이다. 또한, 앞으로도 중동지역에 대한 지원은 국가 정책차원에서 결정될 가능성이 높다. 이러한 외부 환경에 대해 KOICA 등 국제개발협력 관련 기관에서는 중동 지역 국가에 대한 장기적 관점에서 한국의 비교우위를 바탕으로 한 지원 전략을 수립하여 외교안보적 결정 사항 에 대처할 필요가 있다.

한국은 공여국들 중 유일하게 원조를 받았던 경험을 가진 국가라는 점과 식민지 지배와 전쟁을 극 복하고 경제개발에 성공한 경험으로 인해 협력대상국 특히 분쟁지역인 중동에서 그 역할이 크다고 할 수 있다. 이러한 역할을 통해 지금까지 석유와 건설 등 우리는 앞으로 중동과 경제적 협력관계를 뛰어넘어 민주화 경험을 공유하는 더욱 발전된 협력 관계를 구축해 나갈 수 있을 것이다.

지금까지 중동 지역은 이슬람 정교 일치 및 부족주의 등의 특성으로 인해 민주주의가 불가능하다 고 인식되어졌다. 그러나 이번 민주화 혁명을 계기로 그 인식이 바뀌게 되었으며 우리나라의 민주화 경험은 아랍권과 협력관계를 새롭게 구축할 수 있는 좋은 기회가 될 수 있을 것이다. 


\section{참고문헌}

\section{1. 국내문헌}

$\mathrm{KOICA}(2008)$, 국제개발협력의 이해

$\mathrm{KOICA}(2011)$, 한국 $\mathrm{ODA}$ 의 분쟁 및 취약국 지원 방안

$\mathrm{KOICA}(2010)$, 한국형개발협력모델

$\mathrm{KOICA}(2010)$, 한국 ODA의 프로그램형 접근법 도입방안

KOICA 2010년 연보

KOICA 국제개발협력 2010 No. 3

한국수출입은행 통계

$\mathrm{KOICA}(2008)$ 이라크, 이집트 CAS

\section{2. 국외문헌}

IMF world economy outlook 2011

OECD 2009

Norwegian Agency for Development, 2008 